AGH DRILLING, OIL, GAS • Vol. 33 • No. 2 • 2016

http://dx.doi.org/10.7494/drill.2016.33.2.417

\author{
Jan Ziaja*, Vasyl Movchan**
}

\title{
PULLING FORCE SIMULATION OF JET BITS IN RADIAL DRILLING TECHNOLOGY***
}

\section{INTRODUCTION}

Radial drilling technology, which is sometimes called hydraulic drilling with short radius, was developed at $80 \mathrm{~s}$ of past senturies. It is mainly appointed to depleted reservoirs, margin reservoirs and heavy oil reservoirs. Radial drilling technology is much different from traditional drilling technology. The main equipment of this technology consists of a jet bit, a high pressure hose, and a whipstock, as shown in Figure 1. Success of implementation of this technology depends on ability of hydraulic energy to break rock [1]. The flexible high pressure hose is used as the drilling pipe. The whipstock is small enough so that it can enter the main hole smoothly, avoiding underreaming. The high pressure hose is flexible enough to get through the whipstock, which has a track whose axis changes from vertical to horizontal in the ultra-short radius. This equipment can drill few horizontal wells within the same zone up to one hundred meters long. At present time radial drilling technology has been used with good results at different reservoirs in different country, such as Argentina, Bolivia, and Russia [2]. But there are still many difficulties to control the high pressure hose and jet bit trajectory. This and further research on the pulling force of the jet bit is the important step to solve those difficulties. However, little research has been done on the generation of the pulling force of jet bit. Had been made the conclusion that the complex bottom hole flow field can enhance the pulling force of the jet bit. The generation mechanism of the pulling force of the jet

AGH University of Science and Technology, Faculty of Drilling, Oil and Gas, Krakow, Poland

** AGH University of Science and Technology, Faculty of Drilling, Oil and Gas, Krakow, Poland, doctoral student

*** This work was created of the statutory audit in the Faculty of Drilling, Oil and Gas, AGH UST No. 11.11.190.555 
bit remains unclear. The authors wrote mechanical equations for the jet bit and high pressure hose, and analyzed the generation mechanism of the pulling force and the influence of the main.

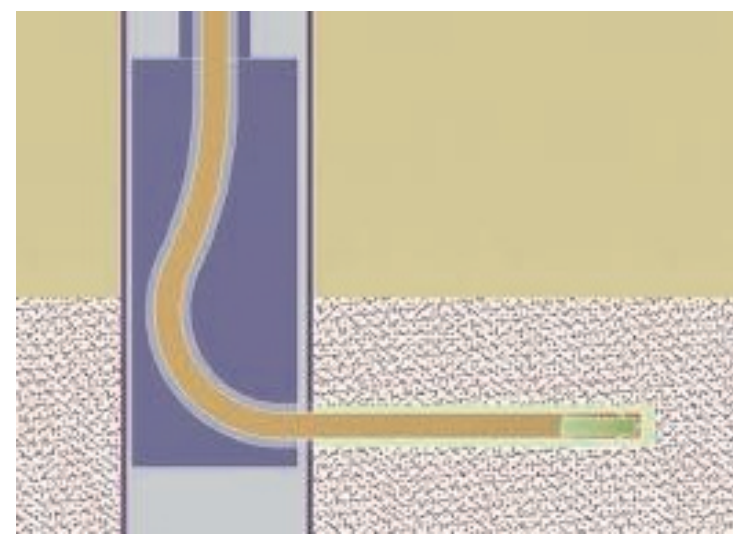

Fig. 1. Radial drilling

\section{WORKING PRINCIPLE OF THE JET BIT}

For simulation would be used well-known and new types of jet drilling bit. The design of multi-jet bit has all advantages of single jet that can generate centralized energy and form a deep borehole depth. The single jet can make a strong impact force within a small area at the bottom, which allow to get a good rock-breaking effect. The rock breaking task is mainly achieved by the central nozzle, while the rest of them assist to rock breaking and expanding the borehole diameter. The main structural parameters are summarized here: backward orifice diameter of the nozzle $d_{1}$, backward orifice diffusion angle of the nozzle $\beta$, forward center orifice diameter of the nozzle $d_{2}$, forward surrounding orifice diameter of the nozzle $d_{3}$, and forward orifice diffusion angle of the nozzle $\alpha$, as shown in Figure 2. Assuming that equivalent diameter of the forward nozzle is $d_{e}$, the orifice number of the forward nozzle is $n$ and each orifice has the same diameter. We can calculate de using the following equation [3]:

$$
\begin{gathered}
m d_{1}^{2}=d_{e 1}^{2} \\
(n-1) d_{3}^{2}+d_{2}^{2}=d_{e 2}^{2}
\end{gathered}
$$

where:

$m$ - borehole number of backward nozzle [-],

$d_{e 1}$ - equivalent diameter of backward nozzle [m],

$n$ - borehole number of backward nozzle [-],

$d_{e 2}-$ equivalent diameter of forward nozzle [m]. 


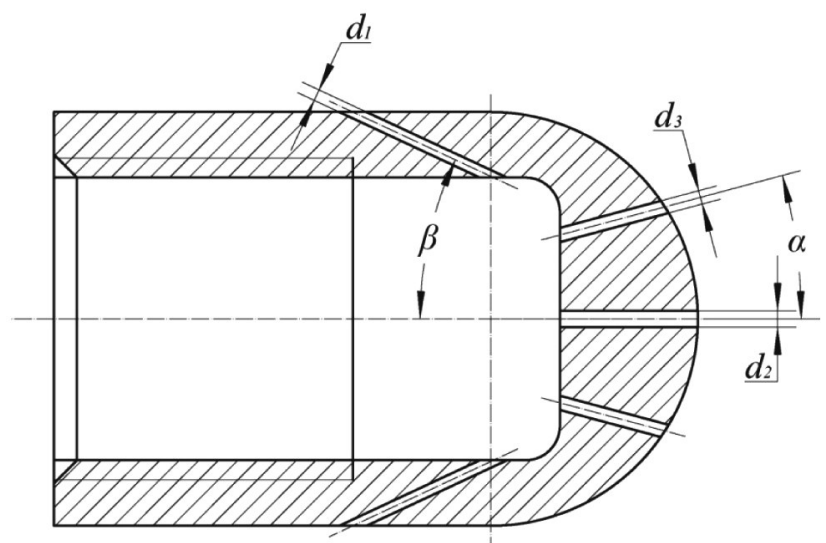

Fig. 2. Hydraulic multi-jet bit

A typical nozzle set has outlets in radial direction for cleaning all nozzles to provide a pulling force. The nozzle head referred to in this study has both forwards and backwards pointing nozzles. The nozzle configuration should have a net pulling force, which enables the nozzle to return to the bottom of the hole after it was pulled out of hole during a clean-up operation. Experimentally was approved that just nozzles do not create an impulse that is sufficient to provide a net pulling force of the magnitude required at drilling process. A minimal force is created by the mass of drilling fluid from the backward nozzles. But as soon as the jets from these nozzles act in annular chamber they will have an ejector effect that will suck away water from the front end of the nozzle head. It keep the low local pressure at the front of the nozzle head. Calculation of the jetting force $S$ in the pulling direction [4]:

$$
S_{c}=\rho v_{0}^{2} A_{0}-\sum_{i=1}^{n} \rho v_{i}^{2} \cos \varphi_{i} A_{i}
$$

where:

$$
\begin{aligned}
& A_{0}=\frac{\pi}{4} D_{0}^{2}-\text { inside hose area }\left[\mathrm{m}^{2}\right], \\
& A_{i}=\frac{\pi}{4} d_{i}^{2}-\text { nozzle area }\left[\mathrm{m}^{2}\right], \\
& v_{0}=\frac{Q}{A_{0}}-\text { inside hose velocity }[\mathrm{m} / \mathrm{s}], \\
& v_{i}=\frac{Q}{n A_{i}}-\text { nozzle velocity }[\mathrm{m} / \mathrm{s}], \\
& n-\text { number of lateral nozzles }[-] .
\end{aligned}
$$


For modeling the process of passing the nozzle head by water had been taken under consideration three different types of nozzle head. Based on received results were calculated pulling forces. All calculation and simulation were done by means of program SolidWorks Flow Simulation.

\section{Model 1}

Water jet drilling bit (Fig. 3) has $9(d=0.5 \mathrm{~mm})$ symmetrical nozzles at the front, which are inclined at an angle of 15 degrees in relative with the axis of the nozzle head. Inner diameter $10 \mathrm{~mm}$ and wall thickness $3.5 \mathrm{~mm}$. Pressure $80 \mathrm{MPa}$.

Fluid flow simulation is pictured in Figure 4.

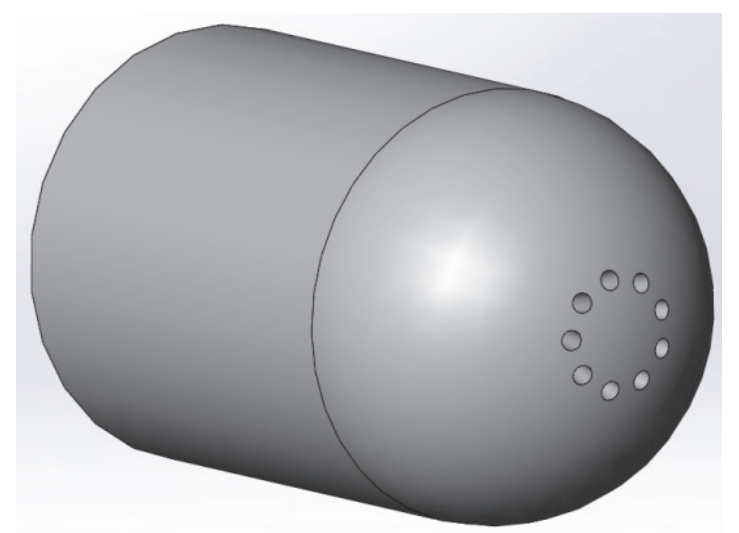

Fig. 3. Woter jet drilling bit
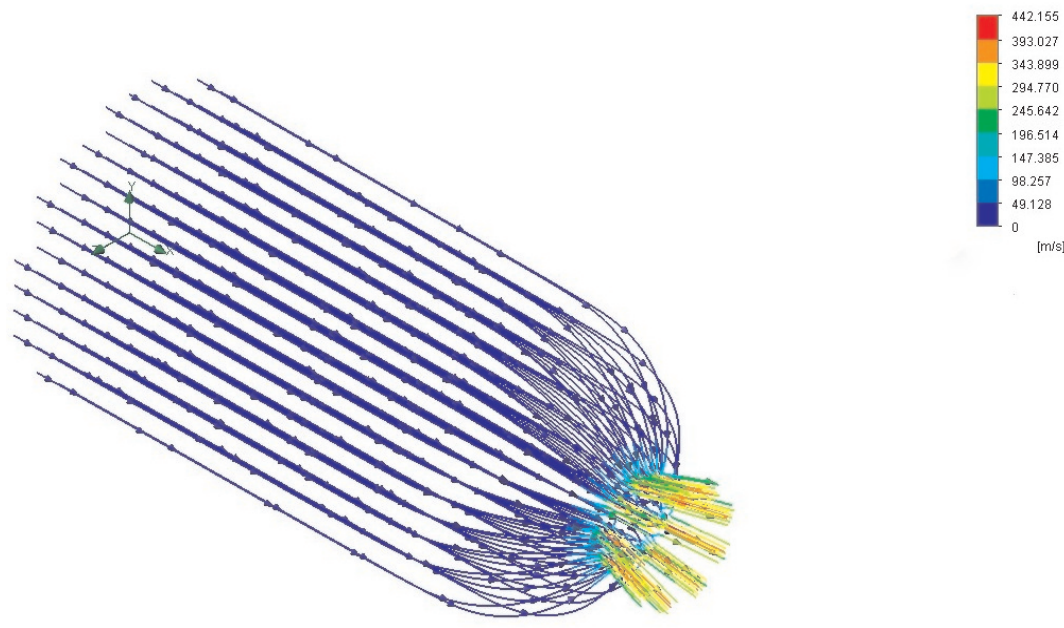

Fig. 4. Fluid flow simulation 


\section{Model 2}

Water jet drilling bit (Fig. 5) has $3(d=0.5 \mathrm{~mm})$ symmetrical nozzles at the front, which are inclined at an angle of 15 degrees in relative with the axis of the nozzle head. At the distance of $25 \mathrm{~mm}$ there are 3 lateral nozzles with diameter 0,5 $\mathrm{mm}$. Outer diameter of nozzle head is $10 \mathrm{~mm}$ with wall thickness $3.5 \mathrm{~mm}$. Length $50 \mathrm{~mm}$. Pressure $80 \mathrm{MPa}$.

Fluid flow simulation is pictured in Figure 6.

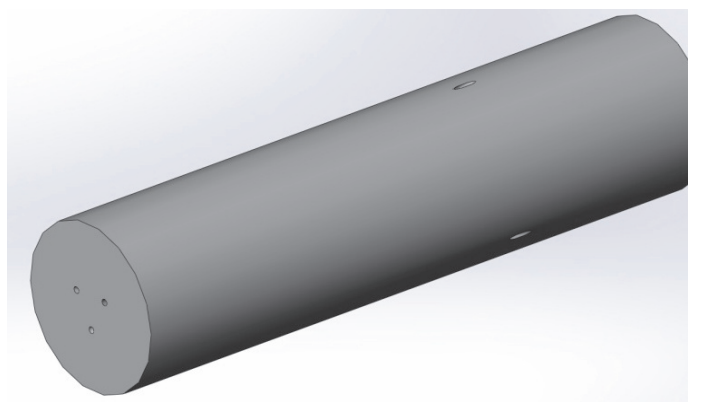

Fig. 5. Water jet drilling bit

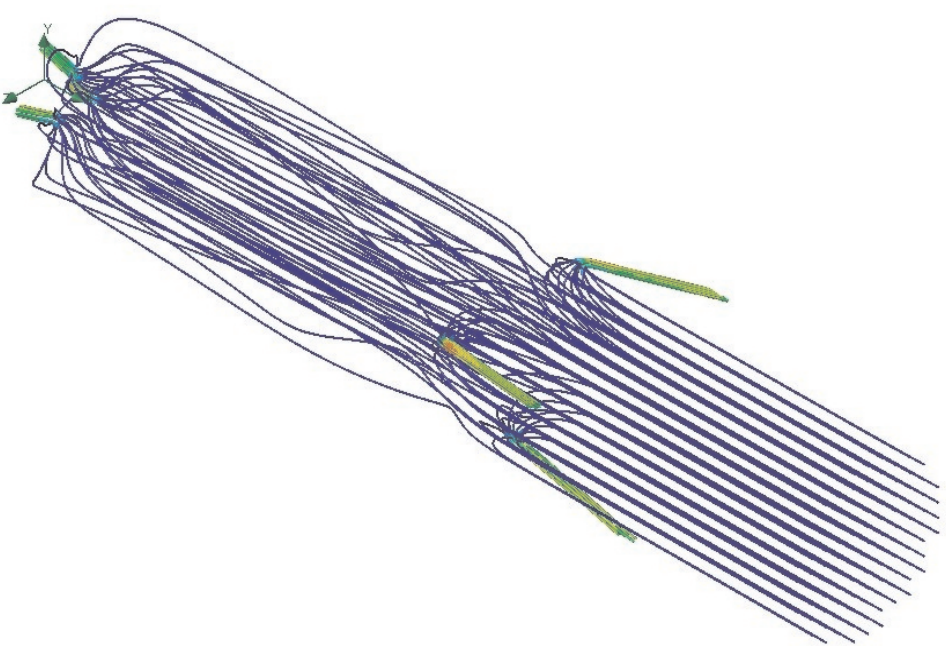

Fig. 6. Fluid flow simulation

\section{Model 3}

Nozzle head has $3(d=0.5 \mathrm{~mm})$ (Fig. 7) symmetrical nozzles at the front, which are inclined at an angle of 15 degrees in relative with the axis of the nozzle head. 
At the distance of $25 \mathrm{~mm}$ there are 6 lateral nozzles with diameter $0.5 \mathrm{~mm}$. Outer diameter of nozzle head is $10 \mathrm{~mm}$ with wall thickness $3.5 \mathrm{~mm}$. Length $50 \mathrm{~mm}$. Pressure $80 \mathrm{MPa}$.

Fluid flow simulation is pictured in Figure 8.

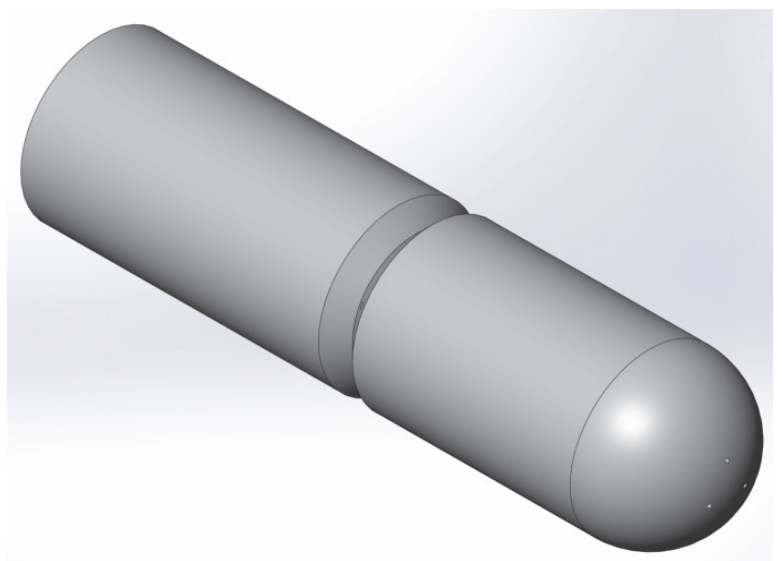

Fig. 7. Water jet drilling bit

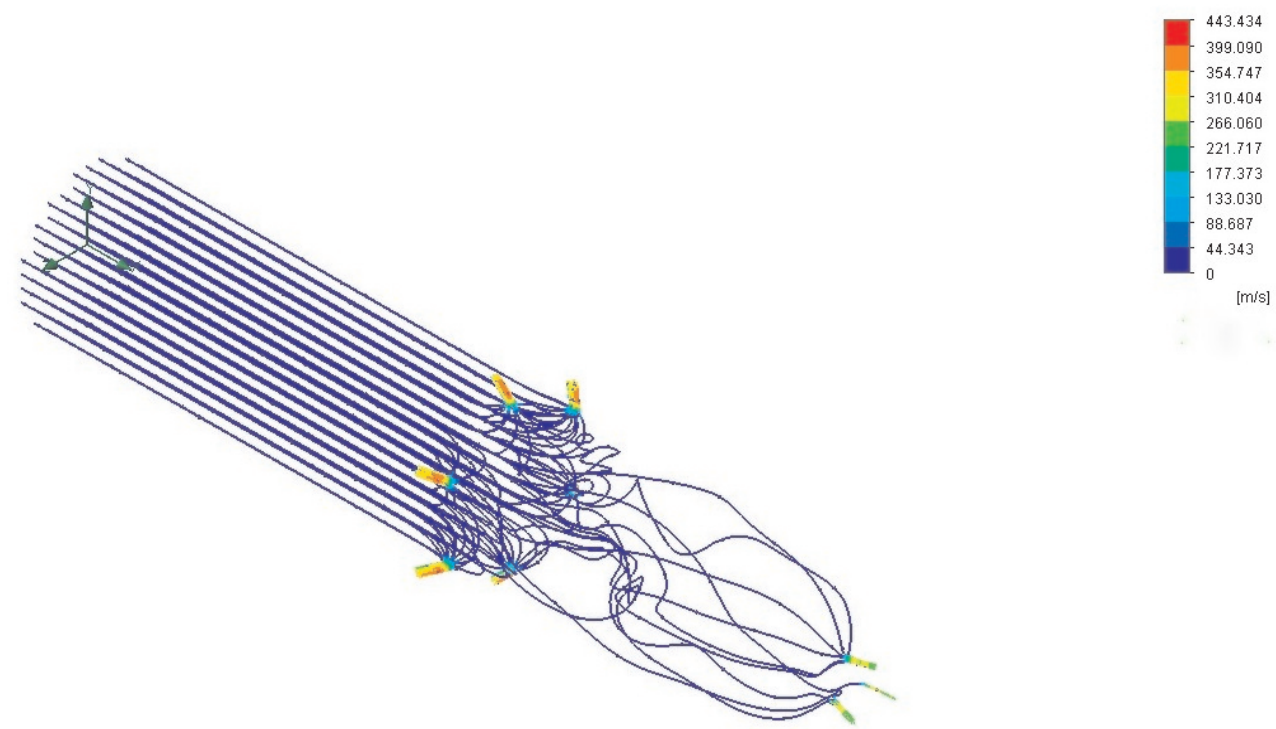

Fig. 8. Fluid flow simulation

During calculating of pulling forces, using taken data from simulation, had been received next results: $S_{1}=42 \mathrm{~N}, S_{2}=105 \mathrm{~N}, S_{3}=311 \mathrm{~N}$. Result shows that using jet bits with backward nozzle can generate increased pulling force. If to continue add backward nozzles, would be logically suggest that pulling force can be significantly bigger. 
So, the quantity of curtained parts is limited by technical aspects. It should be bigger that endurance limits of the rock. Also backward borehole generates the forward force for the jet bit and high-pressure hose to move forward by ejecting fluids backward [5].

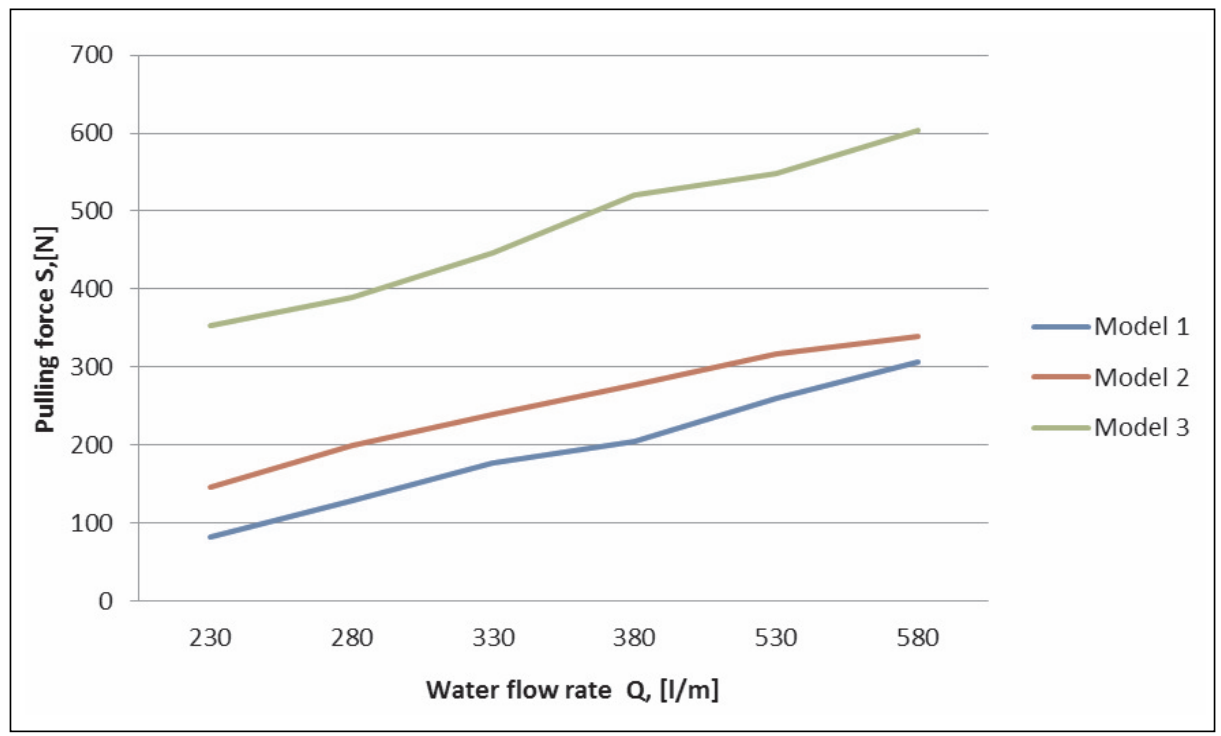

Fig. 9. Correlation between water flow rate and pulling force

Results show that the self-propelled force increases significantly with the increase of the flow rate. Best gain in pulling force is shown in model 3. This is because the total momentum of the jet increases a lot as the increase of flow rate, resulting in a greater reverse thrust for the reverse jet and the effect of pressure drop becomes more obvious. When the flow rate ranges from $380 \mathrm{l} / \mathrm{m}$ to $530 \mathrm{l} / \mathrm{m}$, the range of self-propelled force is from 500 to $560 \mathrm{~N}$ in model 3. Figure 9 shows the relationships between the pulling force of the jet bit and the flow rate of 3 different models. Because the high pressure flexible hose could only bear small axial force, the pulling force was the main factor in keeping the hose steady.

\section{CONCLUSIONS}

1. The newly-designed jet bit can be used to break rock, remove cuttings, enlarge the drill-holes, and to produce pulling force. The depression effect of its backward jets from the backward nozzles reduces the chip hold-down effect, which helps enhance the penetration rate.

2. Calculated and simulated results show that the pulling force reaches $560 \mathrm{~N}$ at a flow rate of $530 \mathrm{l} / \mathrm{m}$. 


\section{REFERENCES}

[1] Buset P. (PGS Intervention AS), Riiber M. (PGS Intervention AS), Eek A. (PGS Reservoir AS): Jet Drilling Tool: Cost-Effective Lateral Drilling Technology for Enhanced Oil Recovery. SPE, 2001.

[2] Adel M. Salem Ragab: Improving well productivity in an Egyptian oil field using radial drilling technique. Journal of Petroleum and Gas Engineering, 2013.

[3] Li Gensheng, Huang Zhongwei, Shen Zhonghou et al.: The method and apparatus for drilling radial horizontal holes by highpressure water jet. China, 101429848A[P], 2009, pp. 05-13.

[4] Yang Ming-Shun, Li Yan, Yuan Qi-Long: A hybrid method to deformation force of high-speed cold roll-beating forming. Journal of Digital Information Management, 11(2), April 2013, pp. 146-153.

[5] Liao Hualin, Niu Jilei, Cheng Yuxiong et al.: Experiment study on water jet breaking rock by multi-orifice nozzle. Journal of China Coal Society, 36 (11), 2011, pp. 1858-1862. 